\title{
Can negative ureteroscopy be predicted in ureteral stone treatment?
}

\author{
Mehmet Oguz Sahin, MD ${ }^{1}$; Volkan Sen, MD, FEBU ${ }^{1}$; Bora Irer, $\mathrm{MD}^{2}$; Guner Yildiz, $\mathrm{MD}^{3}$ \\ ${ }^{1}$ Manisa State Hospital, Department of Urology, Manisa, Turkey; ${ }^{2}$ Izmir Metropolitan Municipality Esrefpasa \\ Hospital, Department of Urology, Izmir, Turkey; ${ }^{3}$ Dr Suat Seren Chest Diseases and Surgery Training and \\ Research Hospital, Department of Urology, Izmir, Turkey
}

Cite as: Can Urol Assoc J 2019 November 29; Epub ahead of print. http://dx.doi.org/10.5489/cuaj.6026

Published online November 29, 2019

$* * *$

\section{Abstract}

Introduction: We aimed to evaluate factors predictive of negative ureteroscopy (URS) in ureteral stones.

Methods: Patients who underwent URS between January 2007 and June 2018 were included in the study. Patients were divided into two groups; group 1: positive URS (841 patients) and group 2: negative URS (75 patients). These two groups were compared in terms of demographic data, stone characteristics, and postoperative outcomes.

Results: The mean age of the study patients was $44.5 \pm 15.1$ years. The absence of collecting system dilatation due to the present stone was found to be a significant predictive factor for negative URS in univariate analysis, but there was no significant difference in multivariate analysis. In the multivariate analysis, low body mass index (BMI), no history of stone surgery, stone located in the distal ureter, small stone area, longer time between the last imaging procedure and URS, and medical expulsive therapy (MET) application were statistically significant in predicting negative URS.

Conclusions: In this study, the parameters that significantly predicted negative URS were found to be low BMI, no history of stone surgery, distal localization of the stone, small stone area, longer time between the last imaging procedure and URS, and MET applied for the current stone. These parameters should be considered to avoid negative URS and patients should be informed of the possibility of negative URS prior to operation. 


\section{Introduction}

Urolithiasis is seen in approximately $15 \%$ of the population and is known to be caused by ureteral stones in $20 \%$ of cases. ${ }^{1}$ In recent years, non-contrast computed tomography (NCCT) has become the preferred method for the diagnosis of ureteral stones with a sensitivity of almost $100 \%{ }^{2}$ However, due to its mutagenic and carcinogenic side effects depending on the amount of radiation exposure, it is recommended that patients undergo repeated computed tomography (CT) only at certain intervals. ${ }^{3}$ The main treatment modalities of ureteral stones are medical expulsive therapy (MET), ureterorenoscopy, and extracorporeal shock wave lithotripsy (ESWL), as well as open or laparoscopic ureterolitotomy that are only rarely employed in recent years. ${ }^{4}$ URS is the most commonly used method of operation and despite the increasing experience of surgeons, complications related to URS or anesthesia is still encountered. In the early period, ureteral injuries, sepsis and even death may occur, while ureteral stenosis develops in the late period. ${ }^{5}$ Considering such negative conditions, MET presents as a significant method for the treatment of particularly $\leq 10 \mathrm{~mm}$ stones. In MET, stone expulsion time varies between four and six weeks, and if it is decided that the stone is not likely to be passed at the end of the waiting period, URS may be required. ${ }^{6}$ However, there is no consensus on the imaging techniques to be used to determine the final status of the stone during or within the waiting period. Although these cases can be evaluated by ultrasonography (USG), intravenous urography (IVU), kidney-ureter-bladder (KUB) or CT, each of these modalities have certain disadvantages in addition to their advantages. In addition, it is not possible to use KUB in the follow-up of non-radiopaque ureteral stones. Despite all imaging modalities and the feedback received concerning whether the patient was able to pass the stone, the stone present in the urinary system is not visualized in $3.8 \%$ to $9.8 \%$ of all URS procedures, which is known as negative-URS. ${ }^{7-9}$

In this study, we investigated the predictive factors in cases that were pre-diagnosed with proximal or distal ureteral stones and were planned to receive an endoscopic ureteral stone treatment with URS, but were found to have no stones in the urinary system during the procedure, and thus were reported as negative-URS.

\section{Methods}

Following the approval of the local ethics committee, 841 patients that underwent endoscopic ureteral stone therapy after being diagnosed with a ureteral stone and found to have one on URS (positive-URS) and 75 patients diagnosed with a ureteral stone that could not be visualized on URS and reported as diagnostic URS (negative-URS) in our clinic between January 2007 and June 2018 were retrospectively evaluated in terms of demographic data, history of urinary system stone disease, localization and other imaging data of the ureteral stone, whether or not MET was applied, time between the last imaging procedure and URS, and operative results. Alpha adrenergic receptor blockers (tamsulosin and silodosin) were used for MET. Tamsulosin $0.4 \mathrm{mg}$ once a day or silodosin $8 \mathrm{mg}$ once a day were used for 3 weeks and the patients were asked to present to the emergency service when needed for the management of pain, drink at least 2.5-3 L/day water, be mobile, and strain their micturition 
into a glass to catch the stones spontaneously passed. The patients were divided into two groups as positive-URS (Group 1) and negative-URS (Group 2) for comparison. For the diagnosis of ureteral stones, NCCT $\left(300 \mathrm{~mA}, 130 \mathrm{kV}, 16\right.$ slice, Alexion - Toshiba ${ }^{\circledR}$, Japan) or USG together with KUB were used. For the calculation of the stone area, the maximum width and length of the stone in mm were multiplied and the result was obtained as $\mathrm{mm}^{2}$. One of the alpha receptor blockers was prescribed to the patients who underwent MET. In addition, 50 $\mathrm{mg}$ /day diclofenac tablets were given orally. The follow-up assessments were undertaken using KUB, USG or CT. A semi-rigid ureteroscope was used in all operations. For all negative-URS cases, the absence of a stone was confirmed by a postoperative NCCT. Patients with multiple or bilateral ureteral stones, those requiring staged procedures, those suspected to have peroperative migration of the stone to the kidney, and those that had previously received a double $\mathrm{J}$ stent were excluded from the study.

For the analysis of the data, the Statistical Package for the Social Sciences (SPSS, Inc., Chicago IL) v. 22 was used. The data were presented as mean \pm standard deviation, number (n) and percentages (\%). P values of $<0.05$ were considered statistically significant. Student's t-test was conducted to compare the continuous variables between the groups and the $\mathrm{X}^{2}$ test for the comparison of categorical variables. The parameters that were found to statistically significantly difference between the groups according to the univariate analysis were further examined using a multivariate analysis to determine their effect on predicting negative-URS.

\section{Results}

A total of 916 patients, $630(68.8 \%)$ male and $286(31.2 \%)$ female, were included in the study. The mean age of these patients was $44.5 \pm 15.1$ years, the mean body mass index (BMI) was $26.3 \pm 3.3 \mathrm{~kg} / \mathrm{m}^{2}$, and the mean stone area was $68.0 \pm 51.8 \mathrm{~mm}^{2}$. Of the stones, $299(32.6 \%)$ were proximal and $617(67.4 \%)$ were located in the distal ureter. URS revealed a ureteral stone in 841 patients $(91.8 \%)$ but no stone was visualized in 75 patients $(8.2 \%)$ during this procedure. The patients' general demographic data, history of urinary system stone disease, and other data related to the current stone and applied procedure are presented in Table 1.

There were $582(69.2 \%)$ male and $259(30.8 \%)$ female patients with a mean age of $44.5 \pm 15.0$ years in Group 1, and $48(64.0 \%)$ male and $27(36.0 \%)$ female patients with a mean age of $44.8 \pm 15.6$ years in Group 2, with no statistically significant difference between the groups ( $p=0.857$ and $p=0.364$, respectively). When the two groups were compared in terms of systemic disease, stone disease history, stone expulsion history, laterality of the current stone, and preoperative NCCT evaluation; no significant difference was observed ( $\mathrm{p}=0.886, \mathrm{p}=0.808, \mathrm{p}=0.903, \mathrm{p}=0.547, \mathrm{p}=0.800$ respectively). The mean $\mathrm{BMI}$ was $26.4 \pm 3.3$ $\mathrm{kg} / \mathrm{m}^{2}$ in Group 1, which was significantly higher compared to Group $2\left(25.2 \pm 2.8 \mathrm{~kg} / \mathrm{m}^{2}\right)$ $(\mathrm{p}=0.003)$. The presence of a history of ESWL was significantly higher in Group $1(\mathrm{n}=86$; $10.2 \%)$ than in Group $2(\mathrm{n}=2 ; 2.7 \%)(\mathrm{p}=0.038)$. Similarly, the history of stone surgery was significantly higher in Group $1(\mathrm{n}=77 ; 9.2 \%)$ compared to Group $2(\mathrm{n}=1 ; 1.3 \%)(\mathrm{p}=0.016)$. When the groups were compared in relation to ureteral localization of the current stone, distal 
stones were more common in Group $2(\mathrm{n}=67 ; 89.3 \%)$ compared to Group 1 ( $\mathrm{n}=550 ; 65.4 \%)$ $(\mathrm{p}<0.001)$. Collecting system dilatation was higher in Group $1(\mathrm{n}=631 ; 75.0 \%)$, than in Group $2(\mathrm{n}=42 ; 56.0 \%)(\mathrm{p}=0.001)$. The stone area was also significantly larger in Group $1(70.9 \pm$ $52.6 \mathrm{~mm}^{2}$ vs $\left.35.5 \pm 22.7 \mathrm{~mm}^{2} ; \mathrm{p}<0.001\right)$. The time between the last imaging procedure and URS was $4.6 \pm 4.9$ /days in Group 1 and $12.1 \pm 7.2$ /days in Group 2 with a statistically significant difference $(\mathrm{p}<0.001)$. A higher percentage of patients in Group $2(\mathrm{n}=20 ; 26.7 \%)$ were found to have received MET for the current stone compared to Group $1(n=23 ; 2.7 \%)$ $(\mathrm{p}<0.001)$. The results of intergroup comparisons are given in Tables 2 and 3 .

The absence of collecting system dilatation due to the present stone was found to be significant predictive factors for negative-URS in univariate analysis, but there was no significant difference in multivariate analysis. In the multivariate analysis, the parameters of a low BMI, no history of stone surgery, stone being located in the distal ureter, small stone area, longer time between the last imaging procedure and URS, and MET application were statistically significant in predicting negative-URS (Table 4).

\section{Discussion}

Although negative-URS is relatively rare, it is a disturbing phenomenon for both the patient and the urologist. Performing a negative procedure may result in unnecessary complications and costs. The main reason for encountering negative-URS is that the diagnosis and treatment of ureteral stones depend very much on preferences and are affected by several factors related to the patient, surgeon and equipment. It is possibly for these reasons that the guidelines related to the diagnosis and follow-up of ureteral stones, the radiographic modality to be used, intervals of follow-up, and when to refer to surgery remain unclear. In addition, it is known that exposure to radiation presents with many risks, especially skin injury, cataract, malignancy, and chromosome damage. ${ }^{10}$ This has led to a shift in the first-choice imaging technique for ureteral stones from NCCT, a radiation imaging modality, to USG in recent years. ${ }^{11}$ However, as the stone size decreases, the sensitivity of USG is also reduced. In addition, NCCT can cause more errors in calculating the size of the stone, and there may also be unnecessary aggressive interventions. ${ }^{12}$ It has previously been reported that the Doppler URS measurement of the urinary jet flow from the ureteral orifices within the bladder could be used to determine the presence of stones in the ureter and predict spontaneous passage. ${ }^{13}$ Most urologists have also adopted the strategy of combining USG with KUB to minimize cumulative radiation exposure due to radiation, which is 4.3 to $6.5 \mathrm{mSv}$ in NCCT, but only 0.2 to $0.7 \mathrm{mSv}$ in KUB. ${ }^{14,15}$ In addition, low-dose CT has been shown to provide successful results, similar to standard-dose CT in the diagnosis of ureteral stones. ${ }^{16}$

In their study conducted with pregnant women suspected to have urolithiasis, White et al. reported a negative-URS rate of $14 \%$. The rate of negative-URS was found to be $23 \%$, $4.2 \%$ and $20 \%$ in cases that underwent renal USG alone, renal USG with low-dose CT, and renal USG with magnetic resonance urography, respectively. ${ }^{17}$ In another study, Youssef et al. evaluated the patients scheduled for surgery due to a ureteral stone using KUB, NCCT or both on the day of operation. The authors noted that $14 \%$ of their patients did not have any stones, 
and their approach avoided unnecessary URS. ${ }^{18}$ In addition to these studies, there are three studies in the literature reporting a negative-URS rate in the range of $3.8 \%$ to $9.8 \% .{ }^{7-9}$ In the current study, negative-URS was detected in $8.2 \%$ of the patients, which is consistent with the literature.

Lambert et al. determined the negative-URS rate to be higher in women than in men. Although the authors could not clearly explain the reason for this, they noted that pelvic phleboliths and parenchymal calcifications associated with medullary sponge kidney were more common in women and might have been confused with a stone. They also stated that women might not notice passage of stone because of urinating in a sitting position and having less dysuria complaints due to their shorter urethra. ${ }^{8}$ In the present study, there were a higher number of female patients in the negative-URS group, but we found no statistically significant difference.

Katafigiotis et al. reported that female gender, presence of a non-radioopaque stone that cannot be detected on KUB, and smaller stone surface area as significant predictive markers for negative-URS. ${ }^{9}$ In our study, the groups did not significantly differ in terms of stone disease and stone passage history. This may be because the patients were able to pass the stone more easily or there were a greater number of non-radiopaque stones. The higher incidence of non-radiopaque stones might be another reason for the ill-informed decisions concerning stone presence on preoperative KUB. In addition, the lack of a difference between the groups in terms of ESWL application for the current stones may also indicate that there was no difference between the groups concerning the distribution of opaque and non-opaque stones, although such a differentiation was not made for all the current stones. In addition, the statistically balanced distribution of patients with a preoperative NCCT diagnosis; i.e., this parameter not resulting in a significant difference can explain why there was no difference between the groups in relation to the accuracy of stone diagnosis. Furthermore, despite the absence of a significant difference between the groups regarding the history of stone disease or stone expulsion, we found a higher rate of negative-URS among patients without a history of stone surgery, which can be attributed to the possibility that these patients had passed smaller stones easier.

Kreshover et al. suggested that the presence of stones located in the distal ureter and a smaller stone size, which had also been reported by Katafigiotis et al., were significant data for predicting negative-URS. ${ }^{7,9}$ Similarly, in our study, we found a higher rate of negativeURS in the presence of distal ureteral stones or in ureteral stones with a smaller area. We believe that this finding is associated with the increased possibility of spontaneous stone passage.

Spontaneous passage through conservative treatment is 71 to $98 \%$ for distal ureteral stones of $<5 \mathrm{~mm}$ and 25 to $53 \%$ for $5-10 \mathrm{~mm}$ stones. ${ }^{19}$ In addition, for proximal, mid and distal localization of ureteral stones, the spontaneous passage rate is reported to be 22,46 and $71 \%$, respectively. ${ }^{20}$ Therefore, the waiting period for stone expulsion usually ranges from four to six weeks. In our study, with the increase of the probability of spontaneous passage of current stones through MET, the rate of negative-URS increased. Furthermore, the higher 
negative-URS rates in parallel with the increased time between the last imaging procedure and URS and absence of pre-operative pain can be explained by the linear relationship between the likelihood of spontaneous stone passage and duration. ${ }^{21,22}$

We found that the possibility of negative-URS was increased in cases with a lower BMI. This may be because these patients were more mobile or their stone diameter was smaller. In contrast to the increased risk of stone formation due to inactivity and high BMI, physical activity alters the transportation of vitamins and minerals in the body that play an important role in the formation of stones. Exercise stimulates thirst, causes excess fluid intake during exercise, and contributes to the chronic expansion of total body water. In general, these effects result in an increase in circulating blood volume of $20-25 \%$, thus increasing urinary excretion. ${ }^{23,24}$ There are studies indicating no relationship between BMI and urinary stone excretion. ${ }^{25}$ On the other hand, depending on the exercise mechanism, similar to the reduction of stone formation, ureteral stone expulsion can be increased.

The lower number of patients with collecting system dilatation in the negative-URS group, which was significant in univariate analysis but ineffective according to multivariate analysis, can be attributed to the smaller area and distal localization of the stones in this group. Supporting this finding is the study by Sahin et al., who showed that the success of MET increased in stones with a smaller proximal ureter diameter and lower degree of hydronephrosis. ${ }^{25}$

The main limitation of this study was its retrospective design. In addition, KUB was not performed in all patients in their initial diagnosis and follow-up; thus, it was not possible to differentiate between opaque and non-radiopaque stones in all cases. Another issue was that pain was evaluated according to the patients' subjective feedback and no pain scale was used. However, the strength of this study was the high number of patients. Using a data set of this size facilitated statistical analysis of the determinants for negative-URS. Our results should be confirmed with further prospective and randomized studies.

In this study, the parameters that significantly predicted negative-URS were found to be low BMI, no history of stone surgery, distal localization of the stone, small stone area, longer time between the last imaging procedure and URS, and MET applied for the current stone. We consider that to avoid negative-URS, these parameters should be taken into account, and the patients should be informed about the possibility of negative-URS before operation. 


\section{References}

1. Dellabella M, Milanese G, Muzzonigro G. Randomized trial of efficacy of tamsulosin, nifedipine and phloroglucinol in medical expulsive theraphy for distal ureteral calculi. J Urol. 2005;174:167-72.

2. Coe FL, Evan A, Worcester E. Kidney stone disease, J Clin Invest. 2005;115:2598608.

3. Brenner DJ, Hall EJ. Computed tomography an increasing source of radiation exposure. N Engl J Med. 2007;357:2277-84.

4. Heers H, Turney BW. Trends in urological stone disease: A 5-year update of hospital episode statistics. BJU Int. 2016;118:785-9.

5. de la Rosette J, Denstedt J, Geavlete P, et al. The clinical research office of the endourological society ureteroscopy global study: indications, complications, and outcomes in 11,885 patients. J Endourol. 2014;28:131-9.

6. Skolarikos A. Medical treatment of urinary stones.Curr Opin Urol. 2018;28:403-7.

7. Kreshover JE, Dickstein RJ, Rowe C, et al. Predictors for negative ureteroscopy in the management of upper urinary tract stone disease. Urology. 2011;78:748-52.

8. Lamberts Remy W, Conti Simon L, Leppert John T et al. Defining the Rate of Negative Ureteroscopy in the General Population Treated for Upper Tract Urinary Stone Disease. J Endourol. 2017;31:266-71.

9. Katafigiotis I, Sabler IM, Heifetz EM, et al. "Stoneless" or Negative Ureteroscopy: A Reality in the Endourologic Routine or Avoidable Source of Frustration? Estimating the Risk Factors for a Negative Ureteroscopy. J Endourol. 2018;32:825-30.

10. Brenner DJ, Hall EJ. Computed tomography an increasing source of radiation exposure. N Engl J Med. 2007;357:2277-84.

11. Ripolles T, Agramunt M, Errando J, et al. Suspected ureteral colic: Plain film and sonography vs unenhanced helical CT. A prospective study in 66 patients. Eur Radiol. 2004;14:129-36.

12. Hangi L, Fucai T, Caixia Z, et al. Limited sensitivity and size over measurements of ultrasound affect medical decisions for ureteral stone compared ton on-contrasted computed tomography. World J Urol. 2019;37:907-11.

13. Ongun $\mathrm{S}$, Teken A,Yilmaz $\mathrm{O}$, et al. Can ureteral jet flow measurement predict spontaneous passage of distal ureteral Stones? Urol Int. 2018;101:156-60.

14. Hyams ES, Shah O. Evaluation and follow-up of patients with urinary lithiasis: Minimizing radiation exposure. Curr Urol Rep. 2010;11:80-6.

15. Mitterberger M, Pinggera GM, Pallwein L, et al. Plan abdominal radiography with transabdominal native tissue harmonic imaging ultrasonography vs unenhanced computed tomography in renal colic. BJU Int. 2007;100:887-90.

16. Poletti PA, Platon A, Rutschmann OT, et al. Low-dose versus standard-dose CT protocol in patients with clinically suspected renal colic. AJR Am J Roentgenol. 2007;188:927-33.

17. White WM, Johnson EB, Zite NB, et al. Predictive value of current imaging modalities for the detection of urolithiasis during pregnancy: a multicenter, longitudinal study. J Urol. 2013;189:931-4.

18. Youssef FR, Wilkinson BA, Hastie KJ, et al. Is pre-operative imaging essential prior to ureteric stone surgery? Ann R Coll Surg Engl. 2012;94:428-31. 
19. Ibrahim AI, Shetty SD, Awad RM, et al. Prognostic factors in the conservative treatment of ureteric stones. Br J Urol. 1991;67:358-61.

20. Miller OF, Kane CJ. Time to stone passage for observed ureteral calculi: a guide for Patient Education. J Urol. 1999;162:688-91.

21. Sáenz Medina J, Alarcón Parra RO, Redondo González E, et al. Prognostic factors of spontaneous expulsion in ureteral lithiasis. Actas Urol Esp. 2010;34:882-7.

22. Turk C, Knoll T, Seitz C, et al. European Association of Urology. Medical Expulsive Therapy for Ureterolithiasis: The EAU Recommendations in 2016. Eur Urol. 2017;71:504-7.

23. Convertino VA. Blood volume: Its adaptation to endurance training. Med Sci Sports Exerc. 1991;23:1338-48.

24. Aune D, Mahamat-Saleh Y, Norat T, et al. Body fatness, diabete, physical activity and risk of kidney Stones: a systemetic review and meta-analysis of cohort studies.Eur J Epidemiol. 2018;33:1033-47.

25. Sahin C, Eryildirim B, Kafkasli A, et al. Predictive parameters for medical expulsive therapy in ureteral stones: a critical evaluation. Urolithiasis. 2015;43:271-5.

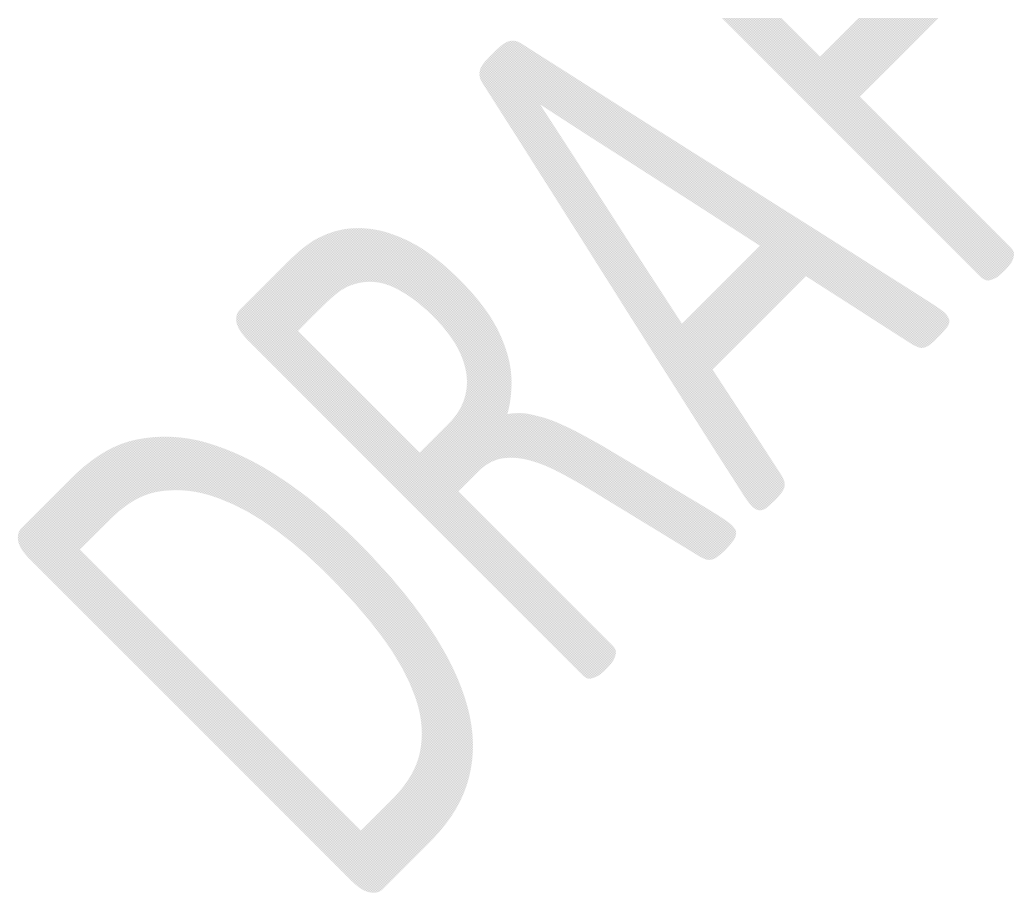


Figures and Tables

\begin{tabular}{|l|c|}
\hline \multicolumn{2}{|l|}{ Table 1. General demographic data and stone characteristics } \\
\hline Age (years) & $44.5 \pm 15.1$ \\
\hline Gender & $630(68.8 \%)$ \\
Male & $286(31.2 \%)$ \\
Female & $26.3 \pm 3.3$ \\
\hline BMI $\left(\mathrm{kg} / \mathrm{m}^{2}\right)$ & $210(22.9 \%)$ \\
\hline Systemic disease & $380(41.5 \%)$ \\
\hline Stone disease history & $88(9.6 \%)$ \\
\hline ESWL history & $376(41.0 \%)$ \\
\hline Stone passage history & $68.0 \pm 51.8$ \\
\hline Stone area (mm $\left.{ }^{2}\right)$ & \\
\hline Stone localization & $299(32.6 \%)$ \\
Proximal & $617(67,4 \%)$ \\
Distal & $673(73.5 \%)$ \\
\hline Collecting system dilatation & $34.8 \pm 19.1$ \\
\hline Operative time (min) & $1.4 \pm 1.3$ \\
\hline Hospitalization time (days) & $75(8.2 \%)$ \\
\hline URS & $841(91.8 \%)$ \\
Negative & \\
Positive & \\
\hline
\end{tabular}

BMI: body mass index; ESWL: extracorporeal shock wave lithotripsy; URS: ureteroscopy.

\begin{tabular}{|c|c|c|c|}
\hline & $\begin{array}{c}\text { Group 1 } \\
\text { Positive URS } \\
(n=841)\end{array}$ & $\begin{array}{c}\text { Group } 2 \\
\text { Negative URS } \\
(n=75)\end{array}$ & $\mathbf{p}$ \\
\hline $\begin{array}{l}\text { Gender } \\
\text { Male } \\
\text { Female }\end{array}$ & $\begin{array}{l}582(69.2 \%) \\
259(30.8 \%)\end{array}$ & $\begin{array}{l}48(64.0 \%) \\
27(36.0 \%)\end{array}$ & 0.364 \\
\hline Age (years) & $44.5 \pm 15.0$ & $44.8 \pm 15.6$ & 0.857 \\
\hline BMI $\left(\mathrm{kg} / \mathrm{m}^{2}\right)$ & $26.4 \pm 3.3$ & $25.2 \pm 2.8$ & 0.003 \\
\hline $\begin{array}{l}\text { System disease } \\
\text { Absent } \\
\text { Present }\end{array}$ & $\begin{array}{l}647(76.9 \%) \\
194(23.1 \%)\end{array}$ & $\begin{array}{l}59(78.7 \%) \\
16(21.3 \%)\end{array}$ & 0.886 \\
\hline $\begin{array}{l}\text { Stone disease history } \\
\text { Absent } \\
\text { Present }\end{array}$ & $\begin{array}{l}491(58.4 \%) \\
350(41.6 \%)\end{array}$ & $\begin{array}{l}45(60.0 \%) \\
30(40.0 \%)\end{array}$ & 0.808 \\
\hline $\begin{array}{l}\text { Stone passage history } \\
\text { Absent } \\
\text { Present }\end{array}$ & $\begin{array}{l}495(58.9 \%) \\
346(41.1 \%)\end{array}$ & $\begin{array}{l}45(60.0 \%) \\
30(40.0 \%)\end{array}$ & 0.903 \\
\hline
\end{tabular}




\begin{tabular}{|c|c|c|c|}
\hline Stone surgery history & $764(90.8 \%)$ & $74(98.7 \%)$ & $\mathbf{0 . 0 1 6}$ \\
Absent & $77(9.2 \%)$ & $1(1.3 \%)$ & \\
Present & \\
\hline
\end{tabular}

BMI: body mass index; URS: ureteroscopy.

\begin{tabular}{|c|c|c|c|}
\hline & $\begin{array}{c}\text { Group 1 } \\
\text { Positive URS } \\
(n=841)\end{array}$ & $\begin{array}{c}\text { Group } 2 \\
\text { Negative URS } \\
(n=75)\end{array}$ & $\mathbf{p}$ \\
\hline $\begin{array}{l}\text { Ureteral localization } \\
\text { Proximal } \\
\text { Distal }\end{array}$ & $\begin{array}{l}291(34.6 \%) \\
550(65.4 \%)\end{array}$ & $\begin{array}{l}8(10.7 \%) \\
67(89.3 \%)\end{array}$ & $<0.001$ \\
\hline $\begin{array}{l}\text { Laterality } \\
\text { Right } \\
\text { Left }\end{array}$ & $\begin{array}{l}402(47.8 \%) \\
439(52.2 \%)\end{array}$ & $\begin{array}{l}39(52.0 \%) \\
36(48.0 \%)\end{array}$ & 0.547 \\
\hline Stone area $\left(\mathrm{mm}^{2}\right)$ & $70.9 \pm 52.6$ & $35.5 \pm 22.7$ & $<0.001$ \\
\hline $\begin{array}{l}\text { Preoperative NCCT } \\
\text { Absent } \\
\text { Present }\end{array}$ & $\begin{array}{l}287(34.1 \%) \\
554(65.9 \%)\end{array}$ & $\begin{array}{l}27(36.0 \%) \\
48(64.0 \%)\end{array}$ & 0.800 \\
\hline $\begin{array}{l}\text { Collecting system dilatation } \\
\text { Absent } \\
\text { Present }\end{array}$ & $\begin{array}{l}210(25.0 \%) \\
631(75.0 \%)\end{array}$ & $\begin{array}{l}33(44.0 \%) \\
42(56.0 \%)\end{array}$ & 0.001 \\
\hline $\begin{array}{l}\text { MET application } \\
\text { Absent } \\
\text { Present }\end{array}$ & $\begin{array}{c}818(97.3 \%) \\
23(2.7 \%)\end{array}$ & $\begin{array}{l}55(73.3 \%) \\
20(26.7 \%)\end{array}$ & $<0.001$ \\
\hline $\begin{array}{l}\text { Time between the last imaging } \\
\text { procedure and URS (days) }\end{array}$ & $4.6 \pm 4.9$ & $12.1 \pm 7.2$ & $<0.001$ \\
\hline
\end{tabular}

MET: medical expulsive therapy; NCCT: non-contrast computed tomography; URS: ureteroscopy.

\begin{tabular}{|c|c|c|c|}
\hline 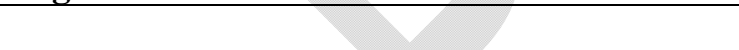 & $\overline{\text { OR }}$ & $95 \% \mathrm{Cl}$ & p \\
\hline BMI & 0.863 & $0.782-0.953$ & 0.004 \\
\hline Stone surgery history & 0.098 & $0.011-0.870$ & 0.037 \\
\hline Ureteral localization (distal ureter) & 2.810 & $1.192-6.622$ & 0.018 \\
\hline Stone area & 0.964 & $0.950-0.978$ & $<0.001$ \\
\hline Collecting system dilatation & 0.783 & $0.421-1.454$ & 0.438 \\
\hline MET application & 4.251 & $1.829-9.877$ & 0.001 \\
\hline $\begin{array}{l}\text { Time between the last imaging procedure and } \\
\text { URS }\end{array}$ & 1.193 & $1.140-1.248$ & $<0.001$ \\
\hline
\end{tabular}

BMI: body mass index; CI: confidence interval; MET: medical expulsive therapy; OR: odds ratio; URS: ureteroscopy. 